\title{
Capacitat predictiva de les variables atribucionals sobre el rendiment acadèmic en Matemàtiques
}

Vicente Molinero Claramunt vicente.molinero.claramunt@gmail.com 
S'analitza longitudinalment la capacitat predictiva d'un conjunt de variables d'estil atribucional cap a l'aprenentatge sobre el rendiment acadèmic en l'àrea de Matemàtiques. Les anàlisis correlacionals i de regressió múltiple es realitzen sobre les dades avaluades en dos moments en una mostra $(\mathrm{N}=180)$ de subjectes que abasta des d'Educació Infantil 5 anys fins a $2 n$ curs d'Educació Primària en contextos educatius formals. S'obté que la dimensió atribucional amb més poder predictiu és la internalitat positiva. Els resultats es discuteixen en termes de les seues implicacions teòriques i pràctiques per a la millora del procés d'ensenyament-aprenentatge.

Paraules clau: estil atribucional, rendiment acadèmic, matemàtiques, Educació Infantil, Educació Primària, internalitat positiva.

\section{Introducció}

Actualment hi ha una gran preocupació en la comunitat educativa davant l'important nivell de fracàs escolar. A Espanya, tal com assenyalen les xifres proporcionades pel Ministeri d'Educació, Cultura i Esport, l'abandonament educatiu primerenc (alumnes que no han assolit la titulació d'Educació Secundària Obligatòria) en el curs 2014-2015 va ser del $21,9 \%$, dada que duplica la mitjana comunitària (11,1 \%).

Les dificultats són especialment destacables en l'àrea de les Matemàtiques on, estudis internacionals d'avaluació, com l'informe PISA (Programme for International Student Assessment), recullen que el 2012, un $24 \%$ de l'alumnat se situava en nivells entre $<1$ i 1 , dels 6 nivells existents, amb la mitjana espanyola 10 punts per sota de la mitjana de l'OCDE (Organització per a la Cooperació i el Desenvolupament Econòmics).

Arran la inquietud generada per l'actual taxa d'abandonament escolar, l'estudi de les variables relacionades amb el rendiment acadèmic constitueix avui dia un dels temes de més interés en la investigació educativa.

L'atribució escolar com a predictor del rendiment acadèmic és la temàtica que més qüestions i incògnites suggereix tant en l'exercici educatiu com en el rendiment acadèmic de l'alumnat. Assíduament s'observa entre els docents expressions com ara: "Què podria fer perquè el meu alumnat estiguera motivat a l'aula? Per què no vol estudiar? Per què el meu alumnat comença el curs amb il.lusió $\mathrm{i}$ al poc temps no mostra interés? Per què a alguns dels meus alumnes els resulta fàcil i plaent I'hàbit d'estudi i, en canvi, a altres els provoca avorriment i repulsió?». Oferir una resposta aclaridora a aquests i altres interrogants similars no suggereix una tasca senzilla. 
Dins el context de les teories sobre la motivació humana, cal destacar la teoria atribucional sobre la motivació i l'emoció (Weiner, 1980, 1986) fruit de la valuosa contribució a l'estudi de la interrelació entre les variables atribucionals $i$ el rendiment acadèmic en les institucions escolars, la qual té, a més, una gran evidència empírica (per exemple, Manassero i Vázquez, 1995; Wambach, 1993; Weiner, 1980, 1986).

En tractar la temàtica de la motivació i considerant els nombrosos enfocaments i variables que es disposen per al seu estudi, hi ha, entre els autors, cert consens sobre els fonaments estructurals que guien el comportament dels individus: la consecució de l'èxit i l'evitació del fracàs.

Weiner (1986) sosté que el comportament motivat està influït per les expectatives d'assoliment d'una meta i el mateix valor d'aquesta, els quals, al seu torn, vénen determinats per les atribucions expressades mitjançant les creences personals sobre quines són les causes originàries tant dels seus èxits com dels seus fracassos. Per això, l'autor, apunta que són les atribucions causals les determinants primàries de la motivació causa de la seua influència sobre les expectatives, les reaccions afectives $i$, en conseqüència, sobre la conducta de rendiment i sobre els resultats que es cullen. Per a l'autor, les creences personals sobre quines són les causes originàries dels seus èxits $\mathrm{i}$ fracassos comporten importants conseqüències tant en l'àmbit emocional, cognitiu i motivacional. A aquestes conseqüències psicològiques Weiner les anomena dimensions atribucionals: (a) internalitat-externalitat (es refereix a la localització de les causes d'uns resultats donats), (b) estabilitat-inestabilitat (es refereix a la durabilitat en el temps d'aquesta localització causal) i (c) controlabilitat-incontrolabilitat (seria la modificabilitat a voluntat de tal factor causal).

Respecte a la primera dimensió, internalitat-externalitat, una atribució causal interna de l'èxit produirà emocions positives com una del fracàs produirà emocions negatives. Al contrari, si l'èxit o el fracàs són atribuïts a causes externes, les emocions patiran canvis limitats. En referència a la segona dimensió atribucional, estabilitat-inestabilitat, Weiner sosté que quan l'individu atribueix a causes estables l'èxit i el fracàs, les seues expectatives futures continuaran en la mateixa senda, prolongant en el temps el mateix èxit o fracàs en diferents contextos $i$ situacions. No obstant això, si l'èxit o el fracàs s'atribueixen a causes inestables, l'individu atresorarà incertesa sobre el que albergarà el futur ja que podrà esdevenir tant en forma d'èxit com de fracàs. Finalment, en la dimensió controlabilitat-incontrolabilitat, l'autor afirma que l'atribució de l'èxit o fracàs a factors controlables pel mateix individu (p. ex., esforç) hi reportarà un increment de la motivació i la persistència, la qual cosa contribuirà a augmentar, probablement i en el context escolar, el rendiment acadèmic. Per tant, si l'èxit o el fracàs es justifiquen mitjançant causes incontrolables (p. ex., atzar o sort), passarà exactament el contrari. Una altra de les dimensions atribucionals vinculades a la motivació, prevista en la teoria de la indefensió apresa (Abramson, Seligman i Teasdale, 1978), és l'especificitat-globalitat, segons la qual resulta 
adaptatiu atribuir tant els èxits a causes globals (generalització) com els fracassos a causes d'índole específica.

Arribats a aquest punt, sembla clar que les dimensions d'estil atribucional (internalitat, estabilitat $\mathrm{i}$ globalitat) exerceixen certa influència sobre el rendiment acadèmic en l'àrea de matemàtiques. Els treballs revisats reflecteixen una tendència investigadora cap a mostres d'alumnes escolaritzats en les etapes d'Educació Primària, Secundària i estudis superiors i/o universitaris. Són escassos els estudis que utilitzen mostres des d'edats primerenques per a valorar la influència de les atribucions sobre el rendiment matemàtic i, encara, són més escassos els treballs desenvolupats des d'un vessant longitudinal. Es considera necessari aprofundir, des de l'etapa d'Educació Infantil i amb caràcter exploratori, en la influència conjunta que exerceixen aquestes variables sobre el rendiment. Aquest serà l'objectiu últim d'aquesta investigació.

\section{Objectius}

Són els redactats seguidament:

1. Analitzar la magnitud de la relació de les conductes atribucionals avaluades en Educació Infantil 5 anys amb les habilitats matemàtiques en 2 n curs d'Educació Primària.

2. Explorar el poder predictiu de les variables atribucionals avaluades en I'últim curs d'Educació Infantil amb les habilitats matemàtiques de $2 \mathrm{n}$.

\section{Material i mètode}

\section{Participants}

La mostra d'estudi inicial (temps 1) estava constituïda per 209 subjectes d'Educació Infantil 5 anys, 47,8 \% xiquetes i 52,2\% xiquets, on el $63,6 \%$ assistien a centres públics i el $36,4 \%$ a centres concertats. Dos cursos escolars després, es va produir el moment d'avaluació del seguiment en $2 \mathrm{n}$ d'Educació Primària (temps 2 ) que dóna una mostra final de 180 subjectes.

Quan es va iniciar la investigació, els subjectes de l'etapa d'Educació Infantil 5 anys tenien una edat compresa entre 5 i 6 anys (mitjana $=70,02$ mesos; DT $=3,61$ ). Dos cursos escolars després, presentaven edats compreses entre 7 i 8 anys (mitjana $=94,16$ mesos; DT =3,78). El Cl equivalent es va mesurar mitjançant les subproves vocabulari i quadrats de l'escala WPPSI-R (Weschler, 1996) seguint les directrius de Spreen i Strauss (1991).

Els subjectes presentaven una mitjana de $\mathrm{Cl}$ equivalent de 98,63 mesos (DT $=12,23$ ). No van formar part de l'estudi aquells subjectes el $\mathrm{Cl}$ equivalent dels quals era inferior o igual a 70, o superior o igual a 130. Així mateix, tampoc no van formar part de l'estudi aquells alumnes amb 
problemes les dificultats dels quals es puguen deure a un trastorn de l'espectre autista (TEA), deficiències sensorials o problema psicològic greu.

En el temps 2 de la investigació, $2 n$ curs d’Educació Primària, únicament el $0,5 \%$ dels subjectes posseïa una Adaptació Curricular Individualitzada $(\mathrm{ACl})$ per a les àrees de Matemàtiques i Llengua Castellana i Literatura. El 19,1\% dels participants assistia a sessions amb un especialista del propi centre: suport $(7,7 \%)$, compensatòria $(1,9 \%)$, pedagogia terapèutica $(3,3 \%)$, audició i llenguatge $(3,8 \%)$ i combinat $(2,4 \%)$. Pel que fa a l'existència d'una necessitat específica de suport educatiu, el $4,4 \%$ dels subjectes presentava les següents: dificultats d'aprenentatge $(1 \%)$, problemes atencionals $(1 \%)$, epilèpsia $(0,5 \%)$, dificultats de la parla i del llenguatge $(0,5 \%)$ i altres $(1 \%)$.

Pel que fa a les famílies, el $88 \%$ de la mostra tenia nacionalitat espanyola mentre que l' $11,5 \%$ procedia d'altres països. Pel que fa al nivell d'estudis dels familiars, el 30,6\% de les mares i el $25,4 \%$ dels pares posseïen estudis universitaris; el $34,9 \%$ de les mares i el $34,4 \%$ dels pares tenien un nivell d'estudis de tipus mitjà (Batxillerat i Formació Professional); i el 33,5\% de les mares i el 39,7\% dels pares posseïen el Graduat Escolar.

\section{Instruments}

\section{Mesures d'estil atribucional emprades en Educació Infantil 5 anys}

Es va administrar el qüestionari Children's Attributional Style Interview (CASI; Conley, C., Haines, B., Hilt, L. i Mestalky, G., 2001) a manera d'entrevista, desenvolupat per a avaluar l'estil atribucional de xiquets a partir de 5 anys.

En aquesta tasca, es mostren a l'alumne una sèrie d'illustracions (16 històries) d'esdeveniments relacionats amb el rendiment (per exemple tasques cognitives, situacions escolars, esport, etc.), que permeten que genere les seues pròpies atribucions i les valore en termes d'internalitat ( $1=$ «depén de mi» vs. $0=$ «depén d'altres») globalitat $(1=$ «passa a tot arreu» vs. $0=$ «ocorre només en un escenari concret») i estabilitat ( $1=$ «passa moltes vegades» vs. $0=$ «passa només aquesta vegada»). La meitat d'esdeveniments posseeix un valor positiu i la resta, negatiu. Les alternatives de resposta es van aplicar de manera contrabalancejada, amb l'objectiu de minimitzar les interferències en les respostes dels subjectes.

La prova posseeix indicadors de fiabilitat i validesa (Conley et al., 2001). Es van prendre com a referència el sumatori de les respostes a cadascun dels índexs del qüestionari. 
Mesures de rendiment matemàtic emprades en $2 n$ curs d'Educació Primària

Es va aplicar la prova estandarditzada Test de Competència Matemàtica Bàsica (TEMA-3; Ginsburg i Baroody, 2007). Es tracta d'un test vàlid $\mathrm{i}$ fiable per avaluar xiquets d'edats compreses entre els 3 anys i 8 anys i 11 mesos. Consta, en total, de 72 elements, presentats en ordre de dificultat creixent, en funció de l'edat, distribuïts en diversos aspectes que valoren tant habilitats com conceptes de caràcter informal (aquelles que el xiquet aprén en contacte amb el seu entorn proper a través d'interaccions no reforçades) i formal (aquelles apreses dins el context escolar). Per a cada alumne, a més de les puntuacions clàssiques (puntuació directa, edat i curs equivalent, índex de competència matemàtica i percentil), s'obté un perfil d'execució, en el qual es reflecteixen les seues fortaleses i debilitats, de manera que la seua anàlisi és un valuós punt de partida per a aclarir les dificultats específiques d'un alumne concret i articular la intervenció.

L'aspecte informal del pensament matemàtic es valora mitjançant 41 ítems distribuïts en quatre components: a) numeració, que valora el domini de la seqüència numèrica, a través de tasques que impliquen habilitats bàsiques i avançades, tant de comptatge com d'enumeració; b) comparació de quantitats, que implica l'habilitat d'establir distàncies relatives entre els nombres; c) càlcul informal, on es plantegen senzilles situacions de suma i resta amb objectes concrets i després es valoren les habilitats de càlcul mental (no necessàriament automàtic), i d) conceptes bàsics, on es considera l'ús de la regla de cardinalitat, la comprensió de la constància numèrica, l'aplicació d'estratègies de comptatge avançades i la comprensió bàsica del repartiment d'objectes.

L'aspecte formal s'avalua mitjançant 31 ítems, al seu torn, també repartits en quatre components: a) convencionalismes de lectoescriptura de quantitats, b) domini de fets numèrics, on es mesura la capacitat de recuperar de manera automàtica el resultat d'operacions de sumar, restar i multiplicar, amb quantitats d'un dígit -les taules-; c) càlcul formal, on es valora tant la seguretat com el procediment seguit, i d) conceptes bàsics relacionats amb el sistema numèric decimal, avaluats mitjançant ítems que impliquen la comprensió del valor posicional i les equivalències entre els diferents ordres de magnitud.

\section{Procediment}

Després d'obtenir els permisos de la Conselleria d'Educació per a dur a terme el projecte de recerca, es va contactar amb els centres educatius sol-licitant la seua participació. Posteriorment, es va obtenir consentiment per escrit per a la participació en la investigació per part dels pares i mares. Amb la finalitat d'abastar un ampli rang de centres, es van seleccionar sis alumnes per aula a l'atzar mitjançant la tècnica del mostreig aleatori simple en centres educatius de les províncies de València i Castelló. 
L'avaluació, la van dur a terme professionals familiaritzats amb l'aplicació i correcció dels tests. L'administració va ser individual, en el temps mitjà d'aplicació que s'estableix en el manual i respectant ritmes individuals. D'altra banda, els espais físics reunien les condicions adequades per a l'avaluació.

En el temps 1, es va administrar el qüestionari CASI a manera d'entrevista i individualment als alumnes d'Educació Infantil 5 anys en horari lectiu sense interferir en les activitats significatives del currículum i al llarg del tercer trimestre del curs escolar. Dos cursos escolars després, en el temps 2, es va tornar als centres escolars on es va administrar la prova estandarditzada TEMA-3 als mateixos subjectes, seguint el mateix procediment descrit anteriorment.

\section{Anàlisis estadístiques}

Per a l'anàlisi estadística, el programa utilitzat va ser el paquet estadístic Statistical Package for the Social Science (SPSS), versió 22.00 (SPSS Inc., Chicago, IL USA).

Per al primer objectiu, es va realitzar una anàlisi de correlacions bivariades utilitzant el mètode estadístic de Pearson entre les diferents variables atribucionals avaluades en Educació Infantil 5 anys i el rendiment matemàtic en $2 n$ curs d'Educació Primària.

En el segon objectiu, es va realitzar una anàlisi de regressió lineal múltiple pel mètode de passos successius per a comprovar quines conductes atribucionals d'Infantil 5 anys predeien les habilitats matemàtiques als 7 anys.

\section{Resultats}

En la taula 1 s'observen els resultats relatius a l'anàlisi de les correlacions bivariades entre les diferents dimensions de l'estil atribucional, tant positives com negatives, avaluades en l'últim curs d'Infantil i el rendiment matemàtic de 2 n curs de Primària.

Són positius tots els resultats obtinguts per a les correlacions de la dimensió atribucional categoritzada com a internalitat positiva. En aquest sentit, resulten més significatives les variables següents: puntuació total $(r=0,176 ; p=0,018)$, numeració informal $(r=0,187 ; p=0,012)$, comparació informal $(r=0,174 ; p=0,019)$, càlcul informal $(r=0,182$; $p=0,015)$ i conceptes informals $(r=0,186 ; p=0,013)$.

Continuant amb la dimensió internalitat positiva i en relació amb les habilitats matemàtiques formals, correlacionen significativament les variables catalogades com a fets numèrics $(r=0,184 ; p=0,014)$, càlcul $(r=0,176 ; p=0,018)$ i conceptes $(r=0,149 ; p=0,046)$. Finalment, cal esmentar que només la variable convencionalismes formal no correlaciona significativament dins de la dimensió atribucional internalitat positiva. 
Una última observació que es desprén dels resultats presentats és la no correlació amb caràcter significatiu entre les dimensions atribucionals internalitat negativa, estabilitat $i$ globalitat respecte a les habilitats matemàtiques avaluades.

Taula 1. Correlacions bivariades entre dimensions positives i negatives de l'estil atribucional (CASI) i el rendiment en matemàtiques (TEMA - 3)

\section{CASI}

\begin{tabular}{|c|c|c|c|c|c|c|}
\hline & \\
\hline & \multicolumn{2}{|c|}{ Internalitat } & \multicolumn{2}{|c|}{ Estabilitat } & \multicolumn{2}{|c|}{ Globalitat } \\
\hline & Positiva & Negativa & Positiva & Negativa & Positiva & Negativa \\
\hline \multicolumn{7}{|l|}{ TEMA-3 } \\
\hline Puntuació total & $.176^{*}$ & 0.22 & 0.95 & -.030 & .072 & -.001 \\
\hline \multicolumn{7}{|l|}{ Habilitats informals } \\
\hline Numeració & $.187^{*}$ & .098 & .128 & -.040 & .077 & .075 \\
\hline Comparació & $.174^{*}$ & .009 & .033 & -.060 & .051 & .027 \\
\hline Càlcul & $.0182 *$ & .061 & .039 & -.028 & .019 & -.014 \\
\hline Conceptes & $.186^{*}$ & .038 & .146 & .054 & .005 & .034 \\
\hline \multicolumn{7}{|l|}{ Habilitats formals } \\
\hline Convencionalismes & .132 & .054 & .074 & -.040 & .026 & .046 \\
\hline Fets numèrics & $.184^{*}$ & .051 & .092 & -.080 & .078 & -.015 \\
\hline Càlcul & $.176^{*}$ & .033 & .134 & -.080 & .027 & -.006 \\
\hline Conceptes & $.149 *$ & .067 & .055 & -.058 & .006 & .008 \\
\hline
\end{tabular}

$* \mathrm{p} \leq .05$

En la taula 2 es presenten els resultats de l'anàlisi de regressió lineal múltiple per passos successius per a les variables d'estil atribucional de l'últim curs d'Infantil pel que fa a les habilitats matemàtiques avaluades als 7 anys.

La variable internalitat positiva explica la variància total de les puntuacions obtingudes per a les diferents subproves de rendiment matemàtic analitzades amb variàncies que oscil.len, en conjunt, entre el $4,1 \%$ i el $2,2 \%$.

De manera desglossada, els resultats obtinguts en la regressió lineal per a les dimensions d'estil atribucional són els assenyalats: puntuació total $\left(\Delta R^{2}=0,041, p=0,006\right)$, numeració informal $\left(\Delta R^{2}=0,035, p=0,012\right)$, comparació informal $\left(\Delta R^{2}=0,030, p=0,019\right)$, càlcul informal $\left(\Delta R^{2}=0,033\right.$, $p=0,015)$, conceptes informals $\left(\Delta R^{2}=0,034, p=0,013\right)$, fets numèrics formals $\left(\Delta R^{2}=0,034, p=0,014\right)$, càlcul formal $\left(\Delta R^{2}=0,031, p=0,018\right) i$ conceptes formals $\left(\Delta R^{2}=0,022, p=0,046\right)$. 
Taula 2. Anàlisi de regressió entre dimensions positives i negatives de l'estil atribucional (CASI) i el rendiment en matemàtiques (TEMA - 3)

\begin{tabular}{llll}
\multicolumn{6}{c}{ CASI } \\
\hline$F$ & $R^{2}$ & $\Delta R^{2}$ & $\beta$ \\
\hline
\end{tabular}

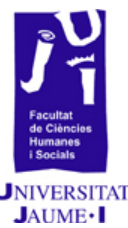

TEMA-3

Puntuació total

$\begin{array}{lllll}\text { Internalitat positiva } & 7.61^{*} & .041 & .041 & .203\end{array}$

Habilitats informals

Numeració

$\begin{array}{llll}\text { Internalitat positiva } & 6.45^{*} & .035 & .035\end{array}$

Comparació

$\begin{array}{lllll}\text { Internalitat positiva } & 5.56^{*} & .030 & .030 & .174\end{array}$

Càlcul

$\begin{array}{lllll}\text { Internalitat positiva } & 6.07 * & .033 & .033 & .182\end{array}$

Conceptes

Internalitat positiva

$6.36^{*}$

.034

.034

.186

Habilitats formals

Fets numèrics

$$
\text { Internalitat positiva }
$$

$6.22^{*}$

.034

.034

.184

Càlcul

Internalitat positiva

$5.72 *$

.031

.031

.176

Conceptes

Internalitat positiva

4.03*

.022

.022

.149

${ }^{*} p \leq .05$

\section{Discussió i conclusions}

El primer objectiu d'aquest estudi longitudinal ha estat examinar la influència de les diferents conductes atribucionals cap a l'aprenentatge en l'etapa d'Educació Infantil 5 anys sobre el rendiment matemàtic en 2 n curs d'Educació Primària.

Els resultats assenyalen una estreta relació entre la dimensió atribucional internalitat positiva i les diferents habilitats matemàtiques. A més, totes les correlacions resulten positives. Aquests resultats van en la línia d'autors com Alonso García et al. (1996), Shanahan i Walberg (1985) i Valle et al. (1998), els quals suggereixen l'existència d'una relació directa, positiva i significativa entre les atribucions causals internes i el rendiment acadèmic. De la mateixa manera, i d'acord amb els resultats, sembla albirar una tendència clara en edats primerenques de l'anomenat 
autoconcepte positiu o locus de control intern positiu on com més atribució dels èxits a un mateix (cosa que comporta sentiments d'autoeficàcia percebuda i autocompetència més grans), més bo serà el rendiment matemàtic. D'acord amb Seegers i Boekaerts (1993), podem afirmar que l'autoconcepte positiu de l'alumnat funciona (ja des d'Educació Infantil 5 anys) com una força motivacional mediadora que incideix sobre el seu propi rendiment.

D'altra banda, cal remarcar que no es van trobar correlacions significatives per a les altres variables d'estil atribucional analitzades (internalitat negativa, estabilitat i globalitat tant en el component positiu com negatiu). Aquest últim resultat està d'acord amb els trobats en diferents investigacions (Cole et al., 2008; Conley et al., 2001; Rholes i Ruble, 1984) on s'exposa que sembla que els alumnes amb edats compreses entre 5-6 anys no mantenen estables i globals seues creences i atribucions causals, tant de manera temporal com situacional, perquè aquestes s'assenten cognitivament i evolutivament al llarg de l'etapa d’Educació Primària.

El segon objectiu pretenia explotar el poder predictiu de les variables atribucionals avaluades en l'últim curs d'Educació Infantil amb les habilitats matemàtiques bàsiques de $2 \mathrm{n}$.

En avaluar la capacitat predictiva de les dimensions d'estil atribucional, com s'esperava, només ha posseït la dimensió internalitat positiva un pes significatiu sobre el rendiment acadèmic amb valors compresos entre el 2,2 \% i el 4,1\%. Així doncs, els resultats recollits en el segon objectiu relatius a les dimensions d'estil atribucional convergeixen en la mateixa direcció, amb les investigacions de Platt (1988) i Relich, Debus i Walker (1986). S'hi exposa que mentre les atribucions causals internes de l'alumnat sobre el seu propi rendiment eren febles (en el nostre cas, amb variàncies entre 2,2\% i 4,1\%), els efectes d'aquestes atribucions sobre l'autoeficàcia percebuda eren consistents, cosa que, al seu torn, tindria un efecte directe sobre el rendiment acadèmic. D'acord amb els resultats del present treball i als estudis d'autors com González i Tourón (1992), Marsh (1984), Marsh i Yeung (1997) i Martínez-Otero (2009), es pot concloure que des d'edats primerenques coexisteixen vincles complexos i entrellaçats entre motivació, atribucions i rendiment acadèmic. De la mateixa manera, també s'observa en l'alumnat d'Educació Infantil una tendència a assignar els èxits acadèmics a factors interns i controlables, la qual cosa comporta l'increment de les seues percepcions d'autoeficàcia percebuda i d'autoconcepte acadèmic, fet que es reproduirà en més interés per aprendre i impulsarà l'ús d'estratègies cognitives amb més freqüència (per exemple, atenció) i persistència en les tasques, influint positivament en el rendiment acadèmic.

En síntesi, sembla que, des de l'etapa d'Educació Infantil, les variables atribucionals $d$ 'autocompetència acadèmica (interés, esforç i persistència per l'aprenentatge) influeixen tant positivament com negativa sobre el rendiment futur. Així mateix, sembla que el pes d'aquestes variables sobre el rendiment augmenta amb l'edat o la promoció a cursos superiors 
en detriment de les variables cognitives. A més, en la mateixa etapa educativa, s'albira també com a determinant del rendiment acadèmic l'assignació de l'èxit en les tasques escolars a causes internes i positives. Finalment, les atribucions causals no es mantenen estables i globals, tant temporal com situacionalment, al llarg de l'etapa d'educació infantil a causa que aquestes s'assenten en etapes educatives posteriors.

Entre les limitacions d'aquest estudi, cal assenyalar la dificultat existent a l'hora d'avaluar variables atribucionals en alumnes de 5 anys. En les diferents investigacions revisades (Chamorro-Premuzic i Furnham, 2006; Colom i Flores-Mendoza, 2007; Deary, Strand, Smith, i Fernandes, 2007; Laidra, Pullman, i Allik, 2007; Miñano i Castejón, 2008, 2011; Watkins, Lei, i Canivez, 2007) es constata la dificultat d'aquest treball ja que, per a estudiar les mateixes variables, s'utilitzen mostres d'alumnes des d'Educació Primària fins a estudis universitaris. Així doncs, el present estudi resulta pioner tant per la novetat com per la seua dificultat, perquè ha estat realitzat amb una finalitat exploratòria, ja que hi ha molt pocs treballs que utilitzen mostres d'Educació Infantil per a analitzar la capacitat predictiva de les variables atribucionals sobre el rendiment amb caràcter longitudinal.

Entre les aplicacions pràctiques que es deriven de l'estudi, s'apunta la necessitat d'incorporar, des de l'etapa d'Educació Infantil, components de caràcter motivacional i d'estil atribucional amb caràcter interdisciplinari per a la formació de l'alumnat i del mateix cos docent.

El docent ha d'acompanyar el seu alumne en el procés d'educar transmetent-li la seua passió i entusiasme per l'aprenentatge, fomentant la reflexió i l'aprofundiment sobre aquest, sent el màxim responsable de la creació d'un clima motivacional positiu a l'aula. Així mateix, ha de prestar especial atenció a aquells alumnes que no es veuen capacitats per a aprendre, de manera que reforce els seus esforços i els seus èxits i premie més pel procés que pel simple producte. El seu gran objectiu és desenvolupar en l'alumne el convenciment que l'estudi i el corresponent aprenentatge són funcionals per a la vida, ajudant, de manera individualitzada, al fet que cada alumne puga fixar-se les seues pròpies metes educatives, incorporant les bastides necessàries que l'ajuden a construir el seu propi camí i li faciliten l'enlairament cap a metes superiors. Per aquest motiu, perquè un alumne progresse en el context escolar, l'acompliment del docent haurà de focalitzar tant en la part instruccional de la matèria (mitjançant activitats funcionals i motivadores en si mateixes que no siguen llargues i amb una dificultat assequible) com en potenciar els sentiments d'autoeficàcia i autocompetència acadèmica com a base de l'èxit educatiu. En definitiva, el docent, com a locomotora de l'èxit, ha de desenvolupar la motivació idònia per a l'aprenentatge en cadascun dels seus alumnes, ha de fortificar dia a dia, d'acord amb l'ús d'interaccions comunicatives multidireccionals i l'ocupació d'estratègies d'aprenentatge cooperatiu-col-laboratiu a l'aula. 
Abramson, L., M. E. P. Seligman i J. D. Teasdale, (1978): «Learned Helplessness in Human: Critique and Reformulation", Journal of Abnormal Psychology, 87, p. 49-74.

Alonso García, E., J. Machargo, G. Méndez, M. Pérez i M. Socorro (1996): "Predicción del rendimiento académico al inicio del Bachillerato", Renovación Pedagógica, 3, 297, p. 1559-1561.

Chamorro-Premuzic, T., i A. Furnham (2006): "Self-assessed Intelligence and Academic Performance», Educational Psycholgy, 26(6), p. 769-779.

Cole, D. A., J. A. Ciesla, D. H. Dallaire, F. A. Jacquez et al. (2008): "Emergence of Attributional Style and its Relation to Depressive Symptoms», Journal of Abnormal Psychology, 117, p. 16-31.

Colom, R. i C. E. Flores-Mendoza (2007): «Intelligence Predicts Scholastic Achievement Irrespective of Ses Factors: Evidence From Brazil», Intelligence, 35(3), p. 243-251.

Conley, C. S., B. A. Haines, L. M. Hilt i G. L. Metalsky (2001): «The Children's Attributional Style Interview: Developmental Tests of Cognitive DiathesisStress Theories of Depression", Journal of Abnormal Child Psychology, 29, p. $445-463$

Deary, I. J., S. Strand, P. Smith i C. Fernandes (2007): «Intelligence and Educational Achievement», Intelligence, 35(1), p. 13-21.

Ginsburg, H., i A. BARoody (2007): Test de Competencia Matemática Básica (TEMA 3), TEA, Madrid.

GONZÁLEZ, M., i J. TOURÓN (1992): Autoconcepto y rendimiento académico. Sus implicaciones en la motivación y en la autorregulación del aprendizaje, EUNSA, Pamplona.

LaidRA, K., H. Pullman, i J. Allik (2007): «Personality and Intelligence as Predictors of Academic Achievement: A Cross-Sectional Study from Elementary to Secondary School», Personality and Individual Differences, 42(3), p. 441-451.

Manassero, M. A., i A. Vázquez (1995): "La atribución causal y la predicción de logro escolar: patrones causales, dimensionales y emocionales», Estudios de Psicología, 54, p. 3-22.

MARSH, H. W. (1984): «Relationship Among Dimensions of Self-attribution, Dimensions of Self-concept, and Academic Achievements", Journal of Educational Psychology, 76, p. 1291-1308.

MARSH, H. W., i A. S. Yeung (1997): "Causal Effects of Academic SelfConcept on Academic Achievement: Structural Equation Models of Longitudinal Data», Journal of Education al Psychology, 89, p. 41-54. 
Martínez-Otero, V. (2009): «Diversos condicionantes del fracaso escolar en la educación secundaria», Revista Iberoamericana de Educación, núm. 51.

MiÑANO, P., i J. L. CASTEJón (2008): «Capacidad predictiva de las variables cognitivo-motivacionales sobre el rendimiento académico», Revista Electrónica de Motivación y Emoción, 28, p. 11-32.

- (2011): «Variables cognitivas y motivacionales en el rendimiento académico en Lengua y Matemáticas: un modelo estructural», Revista de Psicodidáctica, 16(2), p. 203-230.

PlatT, C. W. (1988): «Effects of Causal Attributions for Success on FirstTerm College Performance: A Covariance Structure Model», Journal of Educational Psychology, 80, p. 569-578.

Relich, J. D., R. L. Debus i R. Walker (1986): "The Mediating Role of Attribution and Self-efficacy Variables for Treatment Effects on Achievement Outcomes», Contemporary Educational Psychology, 11, p. 195-216.

RHOLES, W., i D. Ruble (1984): «Children's Understanding of Dispositional Characteristics of Others», Child Development, 71, p. 1662-1671.

Seegers, G., i M. Boekaerts (1993): "Task Motivation an Mathematics Achievement in Actual Task Situations», Learning and Instruction, 3, p. 133-150.

Shanahan, T., i H. J. Walberg (1985): «Productive Influences on High School Student Achievement», Journal of Educational Psychology, 78, p. 357-363.

Valle, A., R. Cabanach, J. C. Núñez i J. A. González-Pienda (1998): «CognitiveMotivational Variables, Approaches to Learning and Academic Achievement», Psicothema, 10, p. 393-412.

WAMBACH, C. (1993): "Motivational Themes and Academic Success of AtRisk Freshmen", Journal of Developmental Education, 16(3), p. 8-10.

Watkins, M. W., P. W. Lei i G. L. Canivez (2007): «Psychometric Intelligence and Achievement: A Cross-Lagged Panel Analysis», Intelligence, 35(1), p. 59-68.

WEINER, B. (1980): Human motivation. Holt, Rinehart and Winston, Nova York.

- (1986): An Attributional Theory of Motivation and Emotion, SpringerVerlag, Nova York. 